\section{Case Reports in Neurology}

Case Rep Neurol 2021;13:239-245

DOI: 10.1159/000515330

Published online: April 13, 2021
(C) 2021 The Author(s)

Published by S. Karger AG, Basel www.karger.com/crn

This article is licensed under the Creative Commons Attribution-NonCommercial 4.0 International License (CC BY-NC) (http://www.karger.com/Services/OpenAccessLicense). Usage and distribution for commercial purposes requires written permission.

\title{
Millard-Gubler Syndrome Associated with Cerebellar Ataxia in a Patient with Isolated Paramedian Pontine Infarction - A Rarely Observed Combination with a Benign Prognosis: A Case Report
}

\author{
Biniyam A. Ayele ${ }^{a} \quad Y_{0}$ Tas Tadesse ${ }^{b} \quad$ Betesaida Guta $^{c} \quad$ Guta Zenebe $^{a}$ \\ aDepartment of Neurology, College of Health Science, Addis Ababa University, \\ Addis Ababa, Ethiopia; 'bepartment of Radiology, School of Medicine, St. Paul \\ Millennium Medical College, Addis Ababa, Ethiopia; ' $Y e h u l e s h e t ~ S p e c i a l t y ~ C l i n i c$, \\ Addis Ababa, Ethiopia
}

\section{Keywords}

Pontine infarction · Stroke $\cdot$ Nystagmus $\cdot$ Ataxia $\cdot$ Ethiopia

\begin{abstract}
Isolated pontine infarction accounts for $7 \%$ of all ischemic strokes. Millard-Gubler syndrome is a clinical syndrome which occurs following lesions involving the ventral portion of the caudal pons, resulting in classic clinical features such as ipsilateral abducens and facial nerve palsy and contralateral hemiparesis. We report the case of a 55-year-old male patient having presented to the Yehuleshet Specialty Clinic 6 years back with sudden-onset dysarthria and appendicular ataxia of 10 days duration. He reported having right hemibody weakness and blurred vision, which have significantly improved since then. He had a history of smoking of 30 pack-years. However, he quit smoking 8 years ago. There was no history of prior stroke, transient ischemic attack, diabetes, hypertension, head trauma, or dyslipidemia. On examination, he had horizontal left gaze palsy with horizontal nystagmus suggesting left-sided 6th cranial nerve palsy. He had mild left-sided facial palsy causing dysarthric speech. Right upper limb dysmetria was observed during examination; otherwise, motor, sensory, fundus, and gait examination results were normal. He had low serum vitamin D. Brain magnetic resonance
\end{abstract}




\section{Case Reports in Neurology}

Case Rep Neurol 2021;13:239-245

DOI: $10.1159 / 000515330$

(c) 2021 The Author(s). Published by S. Karger AG, Basel www.karger.com/crn

Ayele et al.: Paramedian Pontine Infarction in a 55-Year-Old Ethiopian Patient

imaging examination showed a $25 \times 10 \mathrm{~mm}$ segmental lesion in the left median pons involving the basis pontis and tegmentum section. The lesion had T2 and T1 abnormal prolongation with no diffusion restriction, suggesting a subacute pontine infarct. The patient was managed with aspirin $325 \mathrm{mg}$, atorvastatin $80 \mathrm{mg}$, physical therapy, and vitamin D supplementation, and advised on behavioral risk factors. Six years after his isolated pontine infarction, the patient is fully recovered from dysarthria, facial palsy, hemiparesis, right-sided appendicular ataxia, and horizontal nystagmus, and the follow-up brain MRI showed radiological evidence of chronic paramedian pontine perforator infarction. Millard-Gubler syndrome may present with cerebellar ataxia if the paramedian pontine infarction area slightly extends laterally, affecting the middle cerebellar peduncles. Isolated pontine infarction may have a good prognosis if diagnosed and managed early.

(C) 2021 The Author(s)

Published by S. Karger AG, Basel

\section{Introduction}

Pontine infarction accounts for $7 \%$ of all ischemic strokes and $20 \%$ of brain stem strokes [1]. Pontine infarctions can be isolated or not isolated if they present in other parts of the brain [1]. Caudal pontine syndrome can have two patterns of presentation based on the segment of penetrating paramedian vessel affection: proximal and distal occlusion [2]. Likewise, infarction involving the ventral segment of the paramedian pons will result in ventral pontine syndrome, also called Millard-Gubler syndrome (MGS) [3]. The eponymous MGS, an example of crossed hemiplegia, was named after Adolphe Gubler (1821-1879) and Auguste Millard (1830-1915), following their accurate description of the pontine stroke [4]. MGS is defined as a unilateral lesion of the ventral pons at the level of the facial nerve nucleus that presents as unilateral facial nerve and abducens nerve palsy with contralateral hemiplegia [3, 5]. Ventral pontine syndromes are commonly secondary to demyelinating lesions, tumors, trauma, infectious causes, and rarely infarctions [5]. To our knowledge, this is the first case to be reported from the sub-Saharan African region.

\section{Case Presentation}

We report the case of a 55-year-old male patient having presented to the Yehuleshet Specialty Clinic (YSC) 6 years back with sudden-onset dysarthria and appendicular ataxia of 10 days duration. In addition, he reported having right hemibody weakness and blurred vision, which has significantly improved since then. He had a history of smoking of 30 pack-years. However, he quit smoking 8 years ago. His blood pressure and pulse rate were normal. Furthermore, he reported paresthesia of the left upper limb since recent times. There was no history of prior stroke, transient ischemic attack, diabetes, hypertension, head trauma, or dyslipidemia. On examination, he was fully conscious and oriented. He had horizontal left gaze palsy with horizontal nystagmus, suggesting left-sided 6th cranial nerve palsy. He had mild left-sided facial palsy causing dysarthric speech. Right upper limb dysmetria was observed during examination; otherwise, motor, sensory, fundus, and gait examination results were normal.

Routine laboratory investigations showed normal results. The fasting blood sugar level was $342 \mathrm{mg} / \mathrm{dL}$ and hemoglobin $\mathrm{A}_{1 \mathrm{c}}$ was 6.1\%. The serum vitamin $\mathrm{D}$ level was $17.1 \mathrm{ng} / \mathrm{dL}$.

\section{Karger'=}




\section{Case Reports in Neurology}

Case Rep Neurol 2021;13:239-245

DOI: $10.1159 / 000515330$

C 2021 The Author(s). Published by S. Karger AG, Basel www.karger.com/crn

Ayele et al.: Paramedian Pontine Infarction in a 55-Year-Old Ethiopian Patient

Serology tests for HIV, syphilis, and hepatitis B and C virus were negative. The echocardiography, electrocardiography, and carotid Doppler study results were unremarkable. A nerve conduction study of the upper limbs was done for his left hand paresthesia, and it was unremarkable. Brain magnetic resonance imaging (MRI) examination showed a $25 \times 10 \mathrm{~mm}$ segmental lesion in the left median pons involving the basis pontis and tegmentum section. The lesion had T2 and T1 abnormal prolongation with no diffusion restriction, suggesting a subacute pontine infarct (Fig. 1). Magnetic resonance angiography showed normal common carotid, internal carotid, external carotid, and vertebrobasilar arteries (Fig. 2). Diagnosis of MGS was considered, taking into account the clinical evidence, such as: horizontal nystagmus and gaze palsy, which was secondary to ipsilateral abducens palsy; ipsilateral facial palsy, which resulted in dysarthria; the history of right-sided hemiparesis, which had improved upon evaluation; and the MRI evidence of subacute pontine infarction. Factors such as a history of chronic smoking, elevated fasting blood sugar, being male, and old age further supported our assumption of caudal pontine infarction secondary to chronic paramedian pontine perforator blockage over other differential diagnoses of pontine syndromes, such as tumors, demyelinating disorders, neuroinfectious disorders, and vascular malformations.

Subsequently, the patient was managed with aspirin $325 \mathrm{mg}$, atorvastatin $80 \mathrm{mg}$, physical therapy, and vitamin D supplementation and advised on behavioral risk factors. On subsequent follow-up visits, the patient showed significant clinical improvement. Six years after his isolated pontine infarction, the patient has fully recovered from dysarthria, facial palsy, hemiparesis, right-sided appendicular ataxia, and horizontal nystagmus. The follow-up brain MRI showed radiological evidence of chronic paramedian pontine perforator infarction (Fig. 3). Currently, he is on secondary stroke preventive therapy as well as physical and behavioral therapy.

\section{Discussion and Conclusion}

We reported the case of a 55-year-old man with a history of chronic smoking having presented 6 years back to the YSC with clinical features suggestive of MGS and cerebellar ataxia, with brain MRI evidencing left paramedian pontine perforator infarction involving predominantly the ventral segment of the caudal pons. He was started on secondary stroke prevention therapies as he presented late. On a follow-up evaluation 6 years after the first stroke, his neurological signs and symptoms had fully resolved without any residual effect.

Isolated pontine infarctions are classified as either paramedian pontine infarctions (PPI) or lacunar pontine infarctions [6]. This classification helps us to distinguish between the underlying causes of isolated pontine infarctions: PPI is caused by occlusion of perforating branches of the basilar artery (BA), whereas lacunar pontine infarction is caused by small vessel disease [6]. Therefore, the present case falls under the category of PPI. Based on brain MRI, PPI is defined as a lesion extending to the anterior surface of the pons, is often wedge-shaped, and further extends to the basal surface of the pons, which further supports our diagnosis [6].

\section{Pontine Vascular Territory and Neuroanatomic Correlates}

At the level of the pons, we have three vascular territories. The anteromedial section of the pons is supplied by the pontine perforating arteries arising from the BA; these penetrate the basilar sulcus. The anterolateral section is supplied by arteries arising from the anterior inferior cerebellar artery. Finally, the lateral zone is supplied by the lateral pontine

\section{Karger'=}




\section{Case Reports in Neurology}

Case Rep Neurol 2021;13:239-245

DOI: $10.1159 / 000515330$

(c) 2021 The Author(s). Published by S. Karger AG, Basel www.karger.com/crn

Ayele et al.: Paramedian Pontine Infarction in a 55-Year-Old Ethiopian Patient

perforators that arise directly from the BA, from the anterior inferior cerebellar artery, or from the superior cerebellar artery [7]. Anteromedial infarction causes hemiparesis or hemiplegia, contralateral ataxia, dysarthria, nystagmus, and often ipsilateral facial palsy. The anteromedial pons harbors the descending motor fibers, the nuclei of the 6th and 7th cranial nerves, and the pontocerebellar fibers $[1,7]$.

Our patient presented with right-sided hemiparesis, left upper limb ataxia, dysarthria, and left-sided facial and abducens palsy. These clinical features were fairly consistent with lesions involving the neural structures located in the anteromedial pontine section. The absence of contralateral sensory dysfunctions and auditory dysfunction may be explained by the relatively lateral location of spinothalamic fibers and vestibulocochlear nuclei, respectively $[1$, 3, 7-9].

The most common risk factors in previous series of small vessel pontine infarcts have been hypertension, diabetes, and dyslipidemia [10]. Likewise, our patient had multiple risk factors such as being a chronic smoker, having insulin intolerance, being male, and being older. These risk factors likely indicate the atherosclerotic origin of the pontine infarction in the present case. This further supports the need to identify patients at risk of ischemic stroke and the importance of secondary stroke prevention strategies.

MGS is a clinical syndrome which occurs following lesions involving the ventral portion of the caudal pons, resulting in classic clinical features such as ipsilateral abducens and facial nerve palsy and contralateral hemiparesis $[3,5,11,12]$. The present patient presented late to our clinic, and by the time of evaluation he had horizontal nystagmus and gaze palsy from abducens nerve affection, dysarthria from ipsilateral facial muscle weakness, and contralateral (right)-sided appendicular ataxia. By the time of evaluation, he reported having rightsided hemiparesis, which significantly improved in the subsequent days. The paramedian caudal pons contains neural structures including the abducens nucleus, facial nerve fibers, and corticospinal fibers, which were affected in our patient [2]. Furthermore, neural structures such as the middle cerebellar peduncles (MCP) are also in this region [2]. Therefore, the contralateral ataxia observed in our patient could be explained by infarction extending to involve the ipsilateral MCP $[2,3,13,14]$.

Our case shows the importance of brain MRI in differentiating vascular causes of a ventral pontine syndrome from other potential differential diagnoses such as tumors, tuberculoma, neurocysticercosis, demyelinating disorders, and vascular malformations [2]. MGS may present with cerebellar ataxia if the PPI area slightly extends laterally, affecting the MCP. Isolated pontine infarction may have a good prognosis if diagnosed and managed early [15].

\section{Acknowledgements}

We would like to acknowledge the YSC and the patient for their unreserved support.

\section{Statement of Ethics}

The authors' institutions do not require ethical approval for the publication of a single case. Written informed consent was obtained from the patient for publication of this case report and any accompanying images. The completed consent form is available from the corresponding author on reasonable request from the editor.

\section{Karger'=}




\section{Case Reports in Neurology}

Case Rep Neurol 2021;13:239-245

DOI: $10.1159 / 000515330$

(C) 2021 The Author(s). Published by S. Karger AG, Basel www.karger.com/crn

Ayele et al.: Paramedian Pontine Infarction in a 55-Year-Old Ethiopian Patient

\section{Conflict of Interest Statement}

The authors have no conflicts of interest to declare.

\section{Funding Sources}

No funding was received from any organization or individuals.

\section{Author Contributions}

All authors contributed to the conception, evaluation, investigation, diagnosis, management, and follow-up of the patient.

\section{References}

1 Huang J, Qiu Z, Zhou P, Li J, Chen Y, Huang R, et al. Topographic location of unisolated pontine infarction. BMC Neurol. 2019 Aug;19(1):186.

2 Evans MR, Weeks RA. Putting pontine anatomy into clinical practice: the 16 syndrome. Pract Neurol. 2016 Dec;16(6):484-7.

3 Ahmad H, Bukhari MH, Asghar M. Infarction of Ventral Pons Presenting as Millard-Gubler Syndrome: A Case Report. J Rawalpindi Med Coll. 2019;23:128-9.

4 Walusinski O. Adolphe Gubler (1821-1879) or Parisian neurology outside La Salpêtrière in the age of JeanMartin Charcot. Rev Neurol (Paris). 2019 Apr;175(4):207-16.

5 Kannengiesser K, Mahlke R, Petersen F, Peters A, Kucharzik T, Maaser C. Instant evaluation of contrast enhanced endoscopic ultrasound helps to differentiate various solid pancreatic lesions in daily routine. World J Clin Cases. 2019 Jan;7(1):19-27.

6 Yang L, Qin W, Li Y, Yang S, Gu H, Hu W. Differentiation of pontine infarction by size. Open Med (Wars). 2020 Mar;15(1):160-6.

7 Ortiz de Mendivil A, Alcalá-Galiano A, Ochoa M, Salvador E, Millán JM. Brainstem stroke: anatomy, clinical and radiological findings. Semin Ultrasound CT MR. 2013 Apr;34(2):131-41.

8 Numao A, Suzuki K, Iwanami H, Hirata K. Pure sensory stroke due to pontine tegmentum infarction. Intern Med. 2011;50(17):1865.

9 Kim JS, Lee JH, Im JH, Lee MC. Syndromes of pontine base infarction. A clinical-radiological correlation study. Stroke. 1995 Jun;26(6):950-5.

10 Field TS, Benavente OR. Penetrating artery territory pontine infarction. Rev Neurol Dis. 2011;8(1-2):30-8.

11 Ceballos-Lizarraga R, Palomino-Díaz C, Romero-Figueroa JÁ. Wall-Eyed Monocular Internuclear Ophthalmoplegia (WEMINO) and Millard-Gubler Syndromes in a Patient with Isolated Pontine Infarction: Topographic, Oculomotor, and Radiological Analysis of Two Very Uncommon Conditions. Case Rep Neurol. 2019 Jul;11(2):230-7.

12 Onbas O, Kantarci M, Alper F, Karaca L, Okur A. Millard-Gubler syndrome: MR findings. Neuroradiology. 2005 Jan;47(1):35-7.

13 Chang MC, Kwak SG, Chun MH. Dysphagia in patients with isolated pontine infarction. Neural Regen Res. 2018 Dec;13(12):2156-9.

14 Lapa S, Luger S, Pfeilschifter W, Henke C, Wagner M, Foerch C. Predictors of Dysphagia in Acute Pontine Infarction. Stroke. 2017 May;48(5):1397-9.

15 Kataoka S, Hori A, Shirakawa T, Hirose G. Paramedian pontine infarction. Neurological/topographical correlation. Stroke. 1997 Apr;28(4):809-15. 


\section{Case Reports in Neurology}
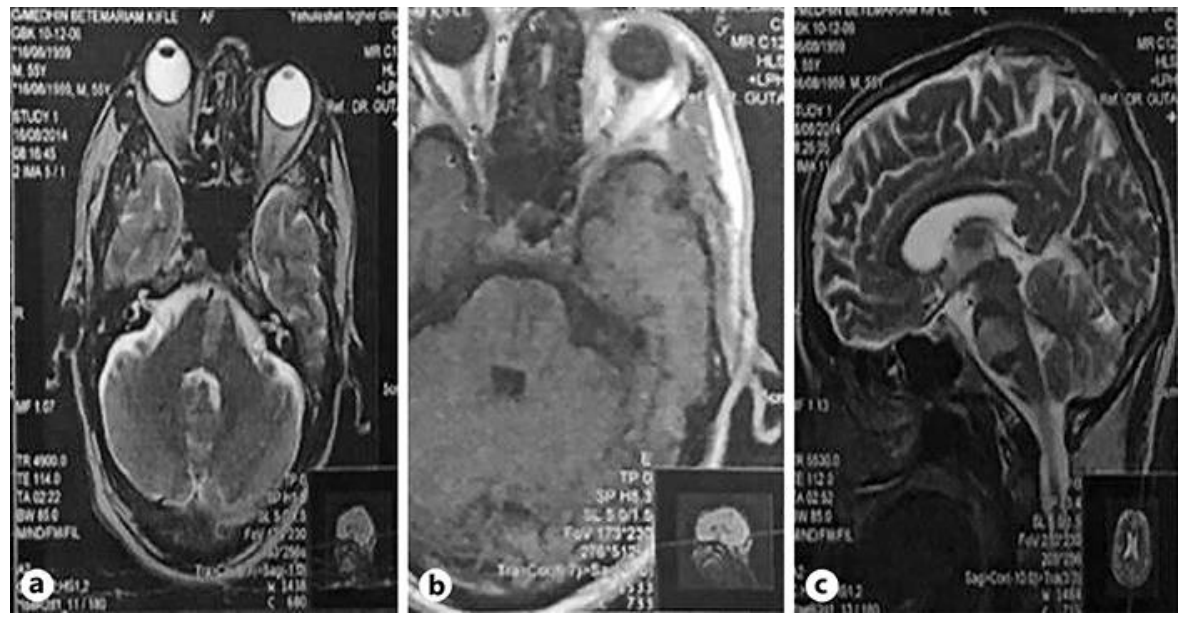

Fig. 1. a Axial T2 brain MRI showing a wedge-shaped segmental hyperintense lesion in the left paramedian pons. b Axial T1 brain MRI showing a wedge-shaped segmental hypointense lesion in the left paramedian pontine region. c Sagittal T2 brain MRI showing a wedge-shaped segmental hyperintense lesion extending from the basis pontis to the tegmentum pontis, indicating subacute infarction.

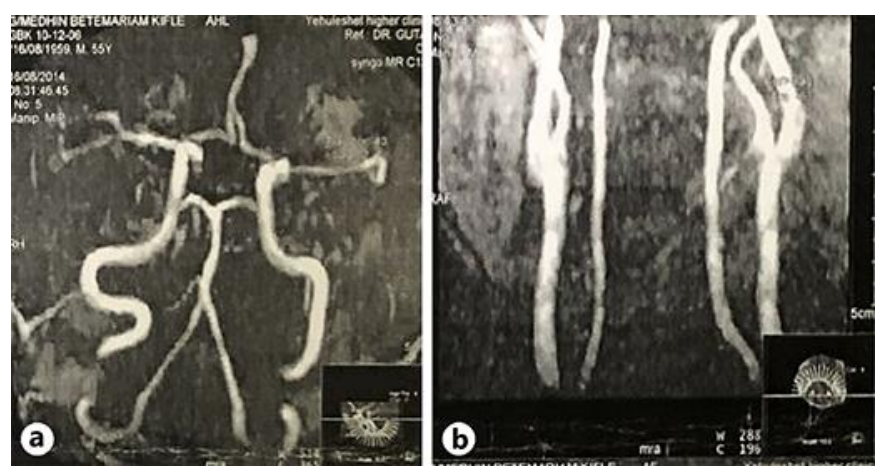

Fig. 2. a Both the common carotid artery and the internal and external carotid arteries were normal and patent, and the circle of Willis and its major branches were well demonstrated. $\mathbf{b}$ Both vertebral arteries were well visualized and normal. 
Case Reports in Neurology
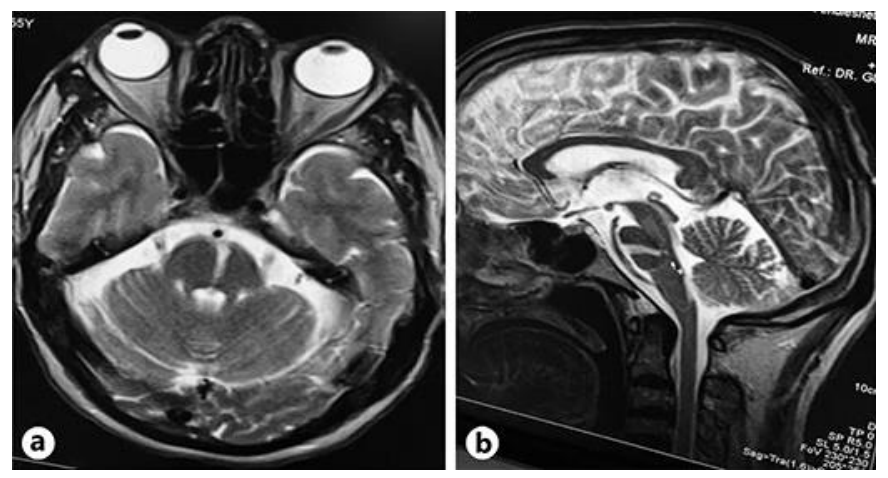

Fig. 3. a Axial T2 brain MRI showing a segmental hyperintense lesion in the left paramedian pons. b Sagittal T2 brain MRI showing a segmental hyperintense lesion extending from the ventral to the dorsal pons, indicating chronic paramedian pontine perforator infarction. 